\title{
CONTRIBUIÇÃO PARA O ESTUDO DA NUTRIÇÃO DE DROSOPHILA WILLISTONI STURT
}

\author{
CELSO PAULO JAEGER \\ (Secçāo de Zoologia -- Instituto de Ciências Natu- \\ rais da Universidade do Rio Grande do Sul - Pôrto \\ Alegre, e Dept. Fisiologia Geral e Animal, Universi- \\ dade de São Paulo)
}

\section{INTRODUÇÃO}

Muitas vêzes, nos estudos da nutrição de organismos é desejável, e mesmo necessária, a determinação de um meio de cultura quìmicamente definido de modo a permitir o desenvolvimento do organismo escolhido em boas condições. Sempre que possível o meio dc nutrição deve ser asséptico, providência esta que elimina a análise c síntese que realizam microorganismos concorrentes, proporcionando assim apreciável redução dos fatôres variáveis, o que é de importância para melhor avaliação dos resultados.

Estudos dêste tipo em animais pluricelulares são relativamente raros na literatura, se considerarmos o grande número de trabalhos r'alizados com micro-organismos.

Nas pesquisas de fisiologia comparada, principalmente, é de interêsse conhecer a influência decisiva no crescimento, na reproduçã̃o, enfim na biologia de certos animais bastante utilizados em diversas pesquisas. Dêstes animais, sobressaem-se pela intensidade de investigação já realizada, as môscas do gênero Drosophila, o díptero de eleição para os estudos de genética, como bem é conhecido. Culturas dêste inseto fazem-se no mundo inteiro, e pareceu-me de inportância verificar a influência que nelas possam exercer certos e determinados fatôres, principalmente os aminoácidos e vitaminas. 
Assim, dispus-me a trabalhar êste tema que me parceu relevante, como contribuição para o melhor conhecimento da biologia das Drosophila.

No presente trabalho tive em mira principalmente o seguinte:

a) determinar um meio de cultura quìmicamente definido no quial D. willistoni pudesse desenvolver-se normalmente, isto é, que permitisse pupação de tôdas ou quase tôdas larvas até atingirem inclusive o estado adulto;

b) experimentar em tal meio de cultura, linhagens de $D$. willistoni oriundas de populações naturais e transformadas em homozigotas para determinado cromosoma, o que possibilitava verificar diferenças bioquímicas em linhagens genèticamente diversas.

Como se sabe, no estudo da genética de populações, a espécie D. willistoni é uma das Drosophilas mais empregadas no Brasil, e daí ser uma das espécies brasileiras mais bem conhecidas genèticamente (Pavan et al. 1951, Cordeiro 1952, 1954), Pavan et al. 1954.

Populações de $D$. willistoni costumam apresentar grandes quanticlades de mutações recessivas, letais, semi-letais, de esterilidade, norfológicas, etc. Evidentemente, muitas outras mutações devem ter passado desapercebidas ao investigador se não utiliza métodos espধciais para conhecê-las. Com êste propósito foi o método da análise espectrofotométrica dos pigmentos do olho de Drosophila empregado por Nolte e outros $(1952,54)$. Por sua vez, Hadorn (1953) preferiu a análise cromatográfica para estudo dos mutantes em linhagens homozigotas aparentemente normais. Recentemente Tondo e Cordeiro (1956), utilizando eletroforese, descreveram "mutantes eletroforéticos". Coube, porém, a Hinton (1951) determinar as mutações netabólicas que afetam necessidades nutricionais nestes Dipteros.

Com a finalidade de proporcionar aos geneticistas mais um método aplicável ao estudo das variações genéticas metabólicas em $D$. willistoni foi êste trabalho realizado por sugestão do Dr. Antônio R. Cordeiro, sob a orientação do Dr. Taylor Hinton no Departamento de Zoologia da Universidade da Califórnia e do Dr. Paulo Sawaya do Departamento de Fisiologia Geral e Animal da Universidade de São Paulo, durante o estágio na Universidade de Los Angeles, gra- 
ças a uma bôlsa de estudos patrocinada pela Fundação Rockefeller. A os Professôres citados que se tornaram credores de minha gratidão adiciono o nome de minha espôsa, Lic. Euterpe Cauduro Jaeger, auxiliar imprescindível na realização dêste trabalho.

\section{MATERIAL E MÉTODOS}

Estoques balanceados de linhagens de $D$. willistoni tornadas horiozigotas para o II cromosoma pelo método empregado por Pavan et al. (1951) seguindo o clássico método CLB, e originárias de môscas coletadas de populações naturais em El Destino, República Argentina, foram gentilmente cedidas pelo Dr. Antônio R. Cordeiro para a realização dêste trabalho.

Coletaram-se os ovos por técnica especial, utilizando um prato raso de vidro provido de uma base de agar-agar a $4 \%$, que era coberta por uma mistura de fermento com Terra de Fuller formando uma camada de um a dois milímetros de espessura sôbre a base de agar. Sôbre o prato assim preparado eram emborcados durante algumas horas garrafas de $1 / 4$ de litro contendo as fêmeas adultas. A camada de fermento e Terra de Fuller assim utilizada era raspada com uma pequena espátula e colocada em cestinhos de tela medindo $1 \mathrm{x}$ $1 \times 0,5 \mathrm{~cm}$ com malha menor que o diâmetro transversal do ovo de D. willistoni. A lavagem dos ovos era feita segurando com uma pinça dois cestinhos de cada vez e aplicando fino jato de água distilada que retirava tôda a mistura de fermento e Terra de Fuller, bem como os detritos visíveis, liberando assim os ovos. A esterilização dos ovos era feita de acôrdo com a técnica de Hinton (1955). Os cestinhos contcndo os ovos eram lavados várias vêzes em água distilada corrente, e anós lavados também várias vêzes em álcool $70^{\circ}$. Depois, colocados durante 45 minutos em placas esterilizadas cobertas com tampa de vidro e novo álcool $70^{\circ}$. A seguir, os cestinhos eram transferidos individualmente para placas de Petri pequenas, devidamente esterilizadas, contendo uma base de agar a $2 \%$. Estas eram guardadas na estufa a $25^{\circ} \mathrm{C}$ durante à noite, para a eclosão dos ovos. Êste tratamento nıstrou-se eficaz e não injuriava os ovos. Na manhã seguinte, utili- 
Zóndo precauções bacteriológicas comuns, as larvas eclodidas eram transftridas para os tubos de ensaio contendo o meio sintético utilizando-se uma alça de platina achatada na ponta. Vinte larvas eram inoculadas por tubo e não mais do que por duas manipulações retiradas da mesma placa de Petri. Como as larvas aderiam fàcilmente à ponta da alça de platina, uma placa de Petri fornecia larvas para dois tubos. Os tubos eram mantidos na estufa a $25^{\circ} \mathrm{C}$ sendo as larvas e pupas contadas diàriamente até a eclosão dos adultos. Os tubos eram então testados, quanto à contaminação, adicionando-se caldo nutritivo e incubando-os por 48 horas na estufa a $37^{\circ} \mathrm{C}$. Em seguida placas de Petri estéreis contendo agar nutritivo eram inoculadas com conteúdo dos tubos e incubadas. De todo tubo que apresentasse contaminação não se considerou nos resultados. As contaminações eram infreqüentes e nunca atingiram mais do que $5 \%$ dos tubos.

TABELA I

Meio de cultura quimicamente definido para $\mathrm{D}$. willistoni

$\begin{array}{lrlr} & \mathrm{mg} / \mathrm{ml} & & \mathbf{u g} / \mathbf{m l} \\ \text { L-Arginina } & 0,559 & \text { Biotina } & \mathbf{0 , 0 2} \\ \text { L-Cisteina } & 0,480 & \text { Pantotenato de Ca } & \mathbf{1 6 , 0} \\ \text { L-ác. Glutâmico } & 4,418 & \text { Colina } & \mathbf{7 5 , 0} \\ \quad \text { Glicina } & 1,745 & \text { ác. Fólico } & 3,0 \\ \text { L-Histidina } & 0,484 & \text { Piridoxina } & 2,5 \\ \text { L-Isoleucina } & 1,260 & \text { Riboflavina } & 10,0 \\ \text { L-Leucina } & 2,345 & \text { Tiamina } & 2,0 \\ \text { L-Lisina } & 1,337 & \text { Niacinamida } & 12,0 \\ \text { DL-Metionina } & 0,339 & & \mathbf{m g} / \mathbf{m I} \\ \text { L-Fenilalanina } & 1,008 & & \\ \text { DL-Treonina } & 0,756 & & 1,83 \\ \text { L-Triptofano } & 1,745 & \mathrm{KH}_{2} \mathrm{PO}_{4} & \\ \text { L-Valina } & 1,355 & & \mathbf{1 , 8 9} \\ & & \mathrm{NaH}_{2} \mathrm{PO}_{4} & \\ \text { Frutose } & 7,5 & & \mathbf{1 , 4} \\ \text { Colesterol } & 0,3 & \mathrm{NaHCO}_{3} & 20,0 \\ \text { ác. Ribonucleico } & 4,0 & \mathrm{Agar} & \end{array}$

O meio sintético era preparado segundo o método descrito por Hinton et al. (1951). Depois de planejada a experiência, colocavamse $20 \mathrm{mg}$ de agar em pó em cada tubo de ensaio utilizando-se um dosador automático. Adicionava-se em seguida o colesterol diluído em 
êter ao agar em cada tubo. Os aminoácidos e açúcar (sacarose ou frutose) foram pesados em quantidades necessárias para $100 \mathrm{ml}$ finais de meio e depois de misturados em moinho de bolas, dissolvidas em $50 \mathrm{ml}$ de água distilada eram neutralizados com $\mathrm{NaOH} 0,1 \mathrm{~N}$. A esta mistura adicionavam-se de soluções estoques, conforme o plano da experiência, ácido nucleico, fosfatos, cloretos, sulfatos (exceto $\mathrm{FeSO}_{4}$ そue era preparado na ocasião), carbonatos e as vitaminas (exceto ácido fólico que era diluído em álcool a 20\%). A seguir juntavam-se $\mathrm{I}^{2} \mathrm{SO}_{4}$ e ácido fólico. Como cada tubo continha $4 \mathrm{ml}$ de meio de cultura e 6 tubos idênticos eram feitos em cada experiência, necessitávámos para uma experiência sòmente $24 \mathrm{ml}$ de meio de cultura. Assim os $100 \mathrm{ml}$ de meio eram divididos em 4 partes de $25 \mathrm{ml}$ cada uma, possibilitando a realização de 4 experiências concomitantes. Depois de divididos os $100 \mathrm{ml}$ em partes iguais eram então adicionadas a) substâncias que representavam as variáveis experimentais. Os meios de cultura finais eram então novamente neutralizados e em seguida pipetados nos tubos de ensaio. Êstes depois de arrolhados com algodão não absorvente eram autoclavados durante 15 minutos a 15 libras de pressão e inclinados para solidificação.

A viabilidade foi medida considerando-se a porcentagem do número original de larvas e o número das que puparam, o tempo médio em dias da inoculação até a pupa e a porcentagem de pupas que produziram adultos. Outros fatôres como o tempo gasto na pupa não foram considerados pois independem do meio de cultura (Hinton et ai., 1951) .

\section{III}

\section{PARTE EXPERIMENTAL}

Com o propósito de estabelecer o meio de cultura quìmicamente dcfinido, de modo a permitir um bom desenvolvimento normal de $D$. $\checkmark \cdot$ illıstoni, inicialmente vários experimentos de contrôle foram realizados e alguns mantidos paralelamente aos meios experimentais durante todo o trabalho. Para provar a eficácia dos meios experimentais utilizaram-se môscas provenientes de fêmeas coletadas na natureza assim como as obtidas pelo intercruzamento de duas linhagens 
diferentes dos estoques mencionados na página 3 , indivíduos agora portadores de dois II cromosomas existentes em animais capturados no ambiente natural (Cordeiro et al., 1958).

Várias fórmulas básicas que deram bons resultados para $D$. melanogaster (Hinton etl al., 1951) foram provadas para D. willistoni, apresentando tôdas elas parco desenvolvimento e longo tempo para puFação em relação ao contrôle.

TABELA II

Experimentos contrôle $-25^{\circ} \mathrm{C}$

\begin{tabular}{|c|c|c|c|c|c|}
\hline $\begin{array}{l}\text { Linhagem } \\
\text { número }\end{array}$ & $\begin{array}{l}N^{\circ} \text { orig. } \\
\text { de larvas }\end{array}$ & Meio d/cultura & $\%$ pupas & $\begin{array}{l}\text { Tempo médio } \\
\text { em dias p/ } \\
\text { pupação }\end{array}$ & $\%$ adultos \\
\hline $220 / 6$ & 120 & Farinha de milho & 75,0 & 9,1 & 95,5 \\
\hline 141 & 120 & $" \quad "$ & 53,3 & 7,4 & 90,6 \\
\hline 8 & 120 & $" \quad "$ & 55,0 & 6,8 & 93,9 \\
\hline 7 & 120 & $" n$ & 76,0 & 6,6 & 86,9 \\
\hline $22 C_{1}$ & 120 & $"$ & 86,6 & 7,0 & 94,2 \\
\hline 38 & 112 & $\begin{array}{l}\text { Fermento morto } \\
\text { Meio para } D . \text { me- } \\
\text { lanogaster }\end{array}$ & 68,8 & 9,6 & 69,1 \\
\hline $220 / 6$ & 91 & Hinton, 18 AA & 43,9 & 17,8 & 75,0 \\
\hline $220 / 6$ & 116 & Hinton, 13 AA & 56,0 & 17,1 & 83,1 \\
\hline $8 / 220$ & 149 & $" n$ & 14,8 & 14,9 & 90,9 \\
\hline $141 / 220$ & 124 & $" \quad "$ & 19,4 & 14,3 & $100,0 *$ \\
\hline $141 / 7$ & 148 & $" n$ & 16,9 & 13,0 & $100,0 *$ \\
\hline $7 / 8$ & 148 & $" n$ & 22,3 & $\mathrm{I} 4,4$ & $100,0 \neq$ \\
\hline Selvagem $* *$ & 115 & Sang, caseina & 11,6 & 7,1 & 22,2 \\
\hline Selvagem & 120 & $"$ & 10,0 & 11,3 & 25,0 \\
\hline Selvagem & 131 & Difco, K 115225 & 33,0 & 17,8 & 77,4 \\
\hline
\end{tabular}

*) Estes dados não são significativos, indicam apenas que tôdas as pupas eclodiram.

**) Linhagens originadas de fêmeas coletadas na natureza e não analisadas genèticamente.

A tabela I sumaria os dados obtidos com êstes meios assim como os experimentos testemunhos com animais homo e heterozigotas. O meio de cultura com caseína Sang, (1956) para D. melanogaster foi também experimentado em $D$. willistoni, segundo a fórmula de Sang, assim como substituindo-se a caseína pela mistura de 13 ami- 
noácidos que contém os 10 essenciais para Drosóphila e mais Cisténa, Glicina e ác. Glutâmico que possuem efeito desintoxicante.

Por cortesia do Dr. Taylor Hinton e dos Laboratórios Difco for: também possível provar o meio experimental K115 225 que possui i mesma composição do usado por Hinton (1951). Êstes meios. não produziram bons resultados conforme sumaria a Tabela II.

Em face da ineficácia dos meios de cultura existentes no toćn nte a permitir o desenvolvimento de $D$. willistoni passamos a pesquisar novas fórmulas. Evidentemente, tôda modificação introduzida que desse bons resultados era logo incorporada no experimento scguinte. Durante o trabalho realizamos 222 experimentos com 76 rneios diferentes quìmicamente definidos (exceção feita dos poucos com caseína e outros com resíduos de fermento). Tôdas experiências foram repetidas no mínimo uma vez. O número de larvas por experiência foi sempre ao redor de 120 (menor em casos de contaminação) o mesmo ocorrendo nas repetiçōes.

a) Necessidades de aminoácidos.

Experimentamos o emprêgo de um número variável de aminoácidos de modo a iniciar com os 10 essenciais para Drosophila (Hintor et al., 1951) e depois aduzir outros em várias combinações dos. não essenciais de tal modo a conseguir misturas de $10,11,13,18 \mathrm{e}$ 10 aminoácidos. Como outra variável experimental, a quantidade de certos aminoácidos foi alterada especialmente dos de efeito desintoxicante, como o ácido glutâmico, a cisteína e a glicina. Uma resposta a doses foi feita para fenilalanina e triptofano. A combinação de aminoácidos que melhores resultados ofereceu foi a de Hintor (1956) contendo 13 aminoácidos nas proporções apresentadas na tabela $\mathrm{I}$.

b) Necessidades de carbohidratos.

Hasset (1948) revisou os trabalhos sôbre necessidades de carbohidratos em insetos e demonstrou os diferentes valores de uma série de açúcares na nutrição de Drosophila adultas. Demonstrou a seguinte ordem de utilização dos açúcares: frutose $>$ maltose $>$ sacarose $>$ glicose $>$ galactose $>$ xilose $>$ lactose. Sang (1956), por sua vez, provou que a frutose é mais conveniente para a Drosophila. 
Frutose na proporção de $7,5 \mathrm{mg} / \mathrm{ml}$ do meio deu melhores resultados com $D$. willistoni do que com sacarose.

\section{c) Necessidades lipoídicas.}

Lecitina, ergosterol e colesterol foram experimentados individualmente em várias concentrações. Lecitina não é essencial para Drosophila (Hinton, 1952, Sang, 195.6). Também aqui verifiquei que - esta substância não melhora as qualidades do meio quando a êle adicionada. Ergosterol utilizado a $0,3 \mathrm{mg} / \mathrm{ml}$ não deu melhores resultados que o colesterol, pois na ausência dêste as larvas não crescem. A quantidade de colesterol que proporciona melhores resultados é de $0,3 \mathrm{mg} / \mathrm{ml}$.

\section{d) Necessidades de ácido nucleico.}

Schultz et al. (1946) e Villee \& Bissel (1948) demonstraram não residir o fator crescimento representado pelo ácido ribonucleico no desenvolvimento de Drosophila no próprio RNA total, mas sim nas bases purínicas e pirimidínicas que o compõem.

Drosophila tem uma capacidade limitada de sintetizar o ácido nucleico de que necessita, e pode fazê-lo se forem fornecidas as bases purínicas e pirimidínicas. Um mutante que perdeu esta capacicáde, não se desenvolve sem adição de adenina (Hinton, 1952). A proporção de RNA e a de seus componentes foram experimentados na dieta. Melhor desenvolvimento obtivemos com $4 \mathrm{mg} / \mathrm{ml}$ de RNA. Tôdas as outras combinações de bases purínicas e pirimidínicas produziram menor efeito. Segundo Sang (1956) uma ótima quantidade de ácido ribonucleico na dieta é suficiente para um bom desenvolvimento.

\section{e) Necessidades de vitaminas.}

Tôdas vitaminas incluídas na tabela III mostraram ser essenciais ao desenvolvimento de $D$. willistoni. Inositol e ácido paraminobenzóico que Hinton (1951) comprovou não serem fator de crescimento para $D$. melanogaster, também não o são para $D$. willistoni . $\mathrm{B}_{12}$ que parece aumentar o número de pupas em $D$. melanogaster rıão tem efeito algum quando retirada da dieta de $D$. willistoni. 


\section{f) Necessidades de sais minerais.}

Sang (1956) demonstrou que as necessidades de sais minerais rẫo podem ser exatamente definidas em meios sintéticos devido à contáminação do agar e outros constituintes com vários metais. As experiências que efetuamos mostram que $D$. willistoni se desenvolve melhor na ausência de $\mathrm{Mg}$, sendo o $\mathrm{K}, \mathrm{P}$ e $\mathrm{Na}$ essenciais.

\section{IV}

\section{DISCUSSÃO}

Os resultados obtidos com o meio sintético para $D$. willistoni tanto para linhagens homo e heterozigotas como para selvagens estão sumariados na tabela III. A análise dêstes dados revela que o meio fornecido foi o melhor conseguido dentro das limitações impostas pelas condições assépticas exigidas por êste tipo de experiência. Evidentemente, não se pode comparar êste crescimento asséptico com o que a môsca encontra na natureza, mas por outro lado pode êle ser confrontado com os experimentos de contrôle (Tabela II) nos quais se deu aos ovos o mesmo tratamento asséptico, utilizando-se meio padrão cle farinha de milho (Burdick, 1954) ou fermento inativo. Os resultados mostram que o melhor meio obtido permitiu a pupação de 70,9 a $99,8 \%$ das larvas inoculadas, no período de 9,3 a 13 dias, resultado aqui considerado bom se comparado com os 6,6 a 9,9 dias de pupação de 69,1 a $96,8 \%$ requeridos por larvas inoculadas em meio de farinha de milho. Para a maior parte das finalidades às quais servirá êste meio sintético esta diferença é de pouca monta.

\section{"Mutações metabólicas"}

O exame dos resultados obtidos criando homozigotos em meio J6: cultura quìmicamente definido para $D$. willistoni (tabela I11) revela que estas linhagens do ponto de vista de sua viabilidade, morfologia, etc., classificadas como normais em meio de cultura comum, apresentam aqui viabilidades diferentes, isto é, mostram diferentes capacidades de aproveitar as substâncias presentes no meio para realizar totalmente suas sínteses orgânicas. 
Estas linhagens são distribuídas numa sequêencia contínua de valores de viabilidade, o que indica a grande diversidade de efeitos produzidos pela homozigose do II cromosoma.

\section{TABELA III}

Resultados obtidos com meio quimicamente definido para $D$. willistoni contends 13 aminoácidos indicados na Tabela $I-25^{\circ} \mathrm{C}$

\begin{tabular}{|c|c|c|c|c|}
\hline $\begin{array}{l}\text { Linhagem } \\
\text { número }\end{array}$ & $\begin{array}{l}N^{\circ} \text { orig. } \\
\text { de larvas }\end{array}$ & $\begin{array}{l}\% \text { de } \\
\text { pupas }\end{array}$ & $\begin{array}{l}\text { Tempo mé- } \\
\text { dio em dias } \\
\text { p/ pupação }\end{array}$ & $\begin{array}{l}\% \text { de } \\
\text { adultos }\end{array}$ \\
\hline Selvagem *) & 120 & 60,0 & 9,6 & 88,8 \\
\hline$"$ & 120 & 70,8 & 9,3 & 70,9 \\
\hline$"$ & 160 & 68,7 & 9,6 & 69,0 \\
\hline$"$ & 180 & 60,0 & 9,5 & 88,9 \\
\hline$"$ & 180 & 61,6 & 13,0 & 78,3 \\
\hline \multicolumn{5}{|l|}{ Homozigotos } \\
\hline 141 & 117 & 33,3 & 13,7 & 74,3 \\
\hline 8 & 104 & 5,8 & 16,0 & 66,7 \\
\hline 8 & 110 & 7,3 & 14,8 & 75,0 \\
\hline 7 & 124 & 26,6 & 14,2 & 75,7 \\
\hline 220 & 123 & 22,7 & 13,7 & 78,6 \\
\hline 38 & 119 & 50,8 & 18,6 & 66,7 \\
\hline 15 & 120 & 45,8 & 23,4 & 67,3 \\
\hline 212 & 119 & 5,0 & 22,7 & $100,0 * *)$ \\
\hline
\end{tabular}

*) Este dado indica apenas que tôdas as pupas desenvolveram adultos.

**) Linhagens originadas de fêmeas coletadas na natureza e não analisadas genèticamente.

As linhagens homozigotas D8 e D212, principalmente, poderiam ser consideradas portadoras de "mutações metabólicas" devido à sua decidida incapacidade de se desenvolverem no meio sintético. Disso decorre a existência de uma provável herança de diferenças bioquímicas oriundas de deficiências nutricionais em consequiência da consição de homozigose.

Embora numerosos experimentos tenham sido realizados, os resultados conseguidos não foram de êxito durante o trabalho de modo a permitir identificar necessidades nutricionais específicas de tais linhagens. Nestes experimentos além de variar individualmente a concentração de diferentes substâncias incluídas na dieta da tabela I fo- 
Tám ainda adicionados em outras experiências as substâncias que aparccem abaixo com as quantidades usadas. Isto na tentativa de identificar alguma mutação metabólica.

$\begin{array}{lc} & \mathrm{mg} / \mathrm{ml} \\ \text { Resíduo de fermento C, } & 2,0 \\ \text { Resíduo de fermento C, } & 2,0 \\ \text { Piridoxamina } & 0,003 \\ \text { Piridoxal } & 0,003 \\ \text { Glutatião } & 0,4 \\ \text { Betaina } & 1,7 \\ \text { Ä́c. cisteico } & 0,5 \\ \text { Citrulina } & \mathbf{1 8 , 0} \\ \text { Homocistina } & 0,4 \\ \text { Homoscrina } & 1,26 \\ \text { Sarcosina } & 1,7 \\ \text { Quinurenina } & 1,7\end{array}$

Até agora o que se conseguiu foi a acentuada incapacidade de Estas Drosophilas se desenvolverem em meio de cultura quìmicamente definido.

\section{V \\ CONCLUSÕES E SUMĀRIO}

1. Teve-se em mira determinar um meio sintético asséptico que possibilite o desenvolvimento de largas de $D$. willistoni.

2. Descreveu-se uma técnica especial para coletar ovos de $D$. willistoni.

3. No meio sintético asséptico determinado experimentou-se a viabilidade de linhagens de $D$. willistoni homozigotas para o II cromosoma .

4. Linhagens que decididamente não se desenvolveram neste meio foram consideradas como portadoras de "mutações metabólicas".

\section{VI \\ SUMMARY}

1. A chemically defined medium for raising D. willistoni in asceptic conditions is formulated. 
2. Special technique for collecting $D$. willistoni eggs is described.

3. On the basis of this medium II chromosome homozygous strains of $D$. willistoni were tested for viability .

4. Strains that consistently failed to grow in this medium were described as carriers of "metabolic mutants".

VI

\section{BIBLIOGRAFIA}

1. BURDICK, A. B., 1954 - New Medium of reproducible quality at room temperature. Drosophila Inf. Service.

2. CORDEIRO, A. A., 1952 - Experiments on the effects in heterozygous condition of second chromosome from natural populations of Drosophila Willistoni. Proc. Nat. Acad. Sci., 38: 471-478.

3. CORDEIRO, A. R., 1954 - Viabilidade de heterozigotos e a dinâmica das populaçóes naturais de Drosophila willistoni. Bol. Inst. Cienc. Nat., 1: $5-54$.

4. Cordeiro, A. R., JAEger, C. P., JAEGER, E. C. \& WOLF, F., 1958 Effects in homozygous condition of chromosomes from natural populations of "Drosophila willistoni". Rev. Brasil. Biol., 18 (3): 283-292.

5. HADORN, E. \& MITCHELL, K. H., 1951 - Properties of mutants of Drosophila melanogaster and changes during development as revealed by paper chromatogrphy. Proc. Nat. Acad. Sci., 37: 650-655.

6. HASSETT, C. C., 1948 - The utilization of sugars and other substances by Drosophila. Biol. Bull., Woods Hole, 95: 114-123.

7. HINTON, T., 1956 - Nucleic acid utilization by Drosophila. Physiol. Zool., 29 (1): 20-26.

8. HINTON, T., ELLIS, J. \& NOYES, D. T., 1951 - An adenine requirement in a strain of Drosophila. Proc. Nat. Acad. Sci., 37: 293-299.

9. HINTON, T., NOYES, D. T. \& ELLIS, J. F., 1951 - Aminoacids and growth factors, in a chemically defined medium for Drosophila. Physiol. Zool, $24,335-353$.

10. HINTON, T. \& ROBERTS, M. R., 1952 - Apparent Mendelian and nonMedelian nucleic acid requiring "mutants" of Drosophila. Genetics, 37: $590-591$.

11. NOLTE, D. J., 1952 -- The eye pigmentary system of Drosophila. III. The action of the eye color genes. J. Gen., 51: 142-186.

12. SANG, J. H., 1956 - The quantitative nutritional requirements of Drosophila melanogaster. Journ. Exper. Biol. 33 (1): 45-72. 
13. SCHULTZ, J., St. LAWRENCE, P. \& NEWMEYER, D., 1946 - A chemicall defined medium for the growth of Drosophila melanogaster. Anat. Rec. 96, 540.

14. TONDO, C. V. \& CORDEIRO, A. R., 1956 - Biophysical Genetics. I Paper electrophoresis separation of the eye pigments and other componentsof "Drosophila". Rev. Brasil. Biol., 16 (4) : 519-526.

15. VILLEE, C. A. \& BISSEL, H. A., 1948 - Nucleic acid as growth factors in Drosophila. J. Biol. Chem. 172: 59-66.

16. PAVAN, C., CORDEIRO, A. R., DOBZHANSKI, N., DOBZHANSKY, Th., MALOGOLOWKIN, C., SPASSKY, B. \& WEDEL, M., 1951 - Concealed genic variability in Brazilian populations of Drosophila willistoni. Genetics, 36: 13-30.

17. PAVAN, C., KNAPP, E., 1954 - The genetic population structure of Brazilian. Drosophila willistoni. Evolution, 8: 303-313. 
